\section{METODOLOGÍA PARA LA VALORACIÓN DEL RIESGO LOCAL, CASO DE ESTUDIO EN TEMOZÓN, MÉXICO}

Delghi Yudire Ruiz Patrón ${ }^{1^{*}}$, Miguel Angel Alonso Cuevas ${ }^{1}$, Christian Israel Aragón Briceño ${ }^{1,2}$, José Efraín Ramírez Benítez ${ }^{3}$ y Sergio Javier Meléndez García ${ }^{4}$

\section{RESUMEN}

En México, los gobiernos locales tienen responsabilidad en procurar la protección civil. Las pequeñas ciudades se encuentran en desventaja por falta de personal capacitado, tecnología y recursos. En este estudio se diseñó una metodología replicable de valoración de Gestión de Riesgo Municipal mediante un análisis heurístico multicriterio en combinación con otros métodos nacionales e internacionales y el cumplimiento de los Objetivos del Desarrollo Sostenible (ODS) local. Se trabajó en 2018 evaluando 12 localidades del municipio de Temozón, México, realizando una investigación diagnóstica-exploratoria, documental y de campo. Se utilizaron instrumentos tipo cuestionario, bitácoras de campo y listas de verificación para evaluar la perspectiva social, municipal, protección civil y las condiciones de las comunidades en relación de los ODS. Para el análisis, se utilizó estadística descriptiva. Se identificó que todas las comunidades estudiadas se encuentran en riesgo alto ante fenómenos hidrometeorológicos, derivado de la alta vulnerabilidad de la población, siendo las más vulnerables Actuncoh e X-Uch. Se concluye que, con la adecuada implementación de acciones de capacitación a través de trabajo participativo con las comunidades y la implementación de un plan de gestión de riesgo municipal, el nivel de riesgo local puede disminuir considerablemente.

\section{PALABRAS CLAVES}

Gestión de Riesgo Municipal, Riesgo Local, ODS, Vulnerabilidad, México

\section{METHODOLOGY FOR THE ASSESSMENT OF LOCAL RISK, CASE STUDY IN TEMOZON, MEXICO}

\section{ABSTRACT}

In Mexico, local governments have a responsibility to provide civil protection. Small cities are at disadvantage due to a lack of trained personnel, technology and resources. In this study, a replicable methodology for assessing Municipal Risk Management was designed using a multicriteria heuristic analysis in combination with other national and international methods and in compliance with the local Sustainable Development Goals or SDGs. The study was carried out in 2018, evaluating 12 locations in the municipality of Temozon Yucaton. It was carried out a diagnosticexploratory, documentary and field investigation, using questionnaire-type instruments, field logs and checklists to assess social, municipal, civil protection and community conditions in relation to the SDGs. For the information analysis, descriptive statistics were used. Results reveal that all the communities studied in Temozón are at high risk for hydrometeorological phenomena, derived from the high vulnerability of the population: being the most vulnerable Actuncoh and X-Uch. Authors assert that, with the adequate implementation of training actions through participatory work with the communities and the implementation of a municipal risk management plan, the level of local risk can decrease considerably.

\section{KEYWORDS}

Municipal Risk Management, Local Risk, SDGs, Vulnerability, Mexico
1. Instituto Tecnológico Superior de Valladolid, Tecnológico Nacional de México, Valladolid, México.

2. Universidad de Twente, Enschede, Países Bajos.

3. Facultad de Ciencias Químico Biológicas, Universidad Autónoma de Campeche, Campeche, México.

4. Universidad Autónoma del Estado de Morelos, Cuernavaca, México.

*Autor de correspondencia: delghi.rp@valladolid.tecnm. $\mathrm{mx}$

Identificador:

http://revistareder.com/ handle-0719-8477-2021-067

\section{RECIBIDO}

6 de mayo de 2020

\section{ACEPTADO}

30 de junio de 2020

\section{PUBLICADO}

1 de enero de 2021

\section{Formato cita}

Recomendada (APA): Ruiz Patrón, D.Y.,

Alonso Cuevas, M.A., Aragón Briceño, C.I., Ramírez Benitez, J.E. \& Meléndez García, S.J. (2021). Metodología para la Valoración del Riesgo Local, Caso de Estudio en Temozón, México. Revista de Estudios

Latinoamericanos sobre Reducción del Riesgo de Desastres REDER, 5(1), 2845. http://revistareder.com/ handle-0719-8477-2021-067

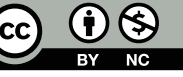

Todos los artículos publicados en REDER siguen una política de Acceso Abierto y se respaldan en una Licencia CreativeCommons Atribución-NoComercial 4.0 Internacional.

Revista de Estudios Latinoamericanos sobre Reducción del Riesgo de Desastres (REDER)

Diseño: Lupe Bezzina 


\section{INTRODUCCIÓN}

En los últimos años, a raíz del incremento poblacional, los cambios geológicos y climáticos en el planeta tierra han incrementado la intensidad y frecuencia de los fenómenos naturales ocasionando impactos negativos como pérdidas humanas, económicas y destrucción del paisaje natural, lo que incide negativamente en la calidad de vida de la población (PNUD, 2011). Según Guha-Sapir et al. (2004), a nivel mundial alrededor de 255 millones de personas en promedio anual tuvieron afectaciones producidas por fenómenos naturales entre 1994 y 2003, de las cuales 58,000 víctimas mortales; entre los años 1990-2000 el costo económico asociado a pérdidas por eventos de origen natural se incrementó 14 veces desde 1950.

Los peligros relacionados con el cambio climático a nivel mundial fueron los causantes del $90 \%$ de los desastres, el $60 \%$ de las muertes y el $98 \%$ de los impactos a nivel mundial en su mayoría en países en desarrollo durante la década de 1990-2000 (IFRC, 2005). Según el Informe Internacional de Desastres (2018) en el periodo 2008-2017 se registraron 3,751 peligros naturales de los cuales $84.2 \%$ estuvieron relacionados con el clima. Solo las inundaciones y tormentas representan el $55 \%$ de los peligros naturales de ese período. Aproximadamente 1,900 millones de personas fueron afectadas, con un costo total de daños por 1,658 millones de dólares en un periodo de 10 años.

En México existen factores que incrementan la vulnerabilidad de los grupos sociales ante eventos naturales tales como la alta densidad poblacional en los centros urbanos, condiciones de vida, el movimiento poblacional así como la contaminación ambiental (Cutter y Finch, 2008). Según el Programa Nacional de Protección Civil de México (Gobierno de la República de México, 2017) los desastres en el período de 2000-2012 afectaron 1,169,000 viviendas y tuvieron un impacto económico de 22,971.2 mdp, comprendiendo afectaciones al sector educativo (23,935 unidades educativas, 4,560.9 mdp) y de salud (1,939 unidades de salud; 4,272.6 mdp). El sector carretero concentró el $57 \%$ del total de los recursos entregados por el Fondo de Desastres Naturales (FONDEN) entre los años 2000 y 2011.

García Acosta (2005) indica que el "riesgo es un conjunto de conocimientos y aceptación, dependiente de la percepción que se tenga de él. La percepción del riesgo es entonces un proceso social y una construcción cultural" (p.16). La construcción social del riesgo ayuda a minimizar los impactos de los fenómenos naturales. Es por ello que se deben tomar en cuenta políticas públicas que actúen de manera preventiva en los temas relacionados con eventos naturales, además de contar con planes de gestión de riesgo local que, de alguna manera, guíen a las municipalidades en cómo afrontar estos temas antes, durante y después de la ocurrencia de algún fenómeno natural.

Para la reducción de los riesgos por fenómenos de origen natural es importante el fortalecimiento de los gobiernos locales en la gestión de riesgo, la formulación de estrategias para capacitar al personal municipal, población expuesta y tener en consideración en el gasto público la prevención de desastres bajo un enfoque de sustentabilidad local.

Por lo tanto, es importante la función que realizan líderes de los gobiernos al interior de sus dependencias locales, pues son quienes se encargan de hacer las gestiones necesarias para el municipio y atendiendo con prioridad aquellos temas relacionados con el desarrollo humano (seguridad, salud y calidad de vida) deben garantizar a través de las políticas ambientales que incluye la gestión de riesgo ante desastres para prevenir pérdidas económicas, humanas y crisis ambientales en la zona de estudio.

En los gobiernos locales en México, el órgano encargado de dar atención al tema de riesgo local es el Sistema de Protección Civil Municipal (SMPC), integrado por el Consejo Municipal, la Unidad Municipal y los representantes de los sectores público, social y privado (Gobierno del Estado de Yucatán, 2017). Por ley los gobiernos municipales están obligados a establecer Consejos Municipales de Protección Civil (CMPC) y a ser los coordinadores más inmediatos ante una situación de emergencia.

De acuerdo al Censo Nacional de Gobiernos Municipales y Delegacionales del Instituto Nacional de Estadística y Geografía (INEGI, 2011), una proporción importante de municipios a nivel nacional no cuenta con una instancia de protección civil local $(1,342$ municipios del país, $54.6 \%$ de ellos). Sin embargo, el hecho de que exista dicha dependencia no significa que tenga presupuesto suficiente, personal capacitado o recursos técnicos que sustenten adecuadamente sus responsabilidades, además de que enfrentan retos institucionales internos ligados a elección 
de representantes sin las capacidades e instrucciones necesarias para la coordinación del cargo como directores de las Unidades Municipales de Protección Civil (UMPC) o permanecen por un período corto de tiempo ( 2 a 3 años) en el cargo con lo que nunca se llega a tener experticia en dichas funciones, tal es el caso de los municipios del oriente del Yucatán.

Porlo tanto, en esta investigación se pretende realizar un estudio que proponga una metodología sencilla para evaluar la gestión de riesgo municipal, con la finalidad generar procedimientos que los mismos organismos locales puedan realizar para obtener una mejora continua en el tema, identificar potenciales peligros naturales, capacitar a sus pobladores y funcionarios públicos, hacer de las localidades y comisarias del interior del municipio autosuficientes y resilientes en el tema de riesgos naturales, así como en general mejorar la gestión del riesgo local.

El objetivo de este estudio fue diseñar una metodología de evaluación de la gestión de riesgo municipal (local) para el análisis de parámetros de peligro, exposición y vulnerabilidad de la población del municipio de Temozón, Yucatán. La Hipótesis general es: el municipio de Temozón tiene un nivel de valoración de riesgo alto ante la ocurrencia de peligros por fenómenos naturales. Las principales limitantes identificadas para el desarrollo de este proyecto fueron la falta de recursos humanos y económico, así como poca o nula información disponible para comparación de los resultados obtenidos, ya que no se ha realizado un estudio similar que tome en cuenta las necesidades del marco de Sendai, los ODS y que haya sido aplicado a las comunidades locales (incluyendo comisarias) incluyendo la percepción social del riesgo.

\section{METODOLOGÍA}

\section{Población y muestra}

El estudio se realizó en el municipio de Temozón ubicado en la zona nororiente del estado de Yucatán, entre los paralelos $20^{\circ} 48^{\prime \prime}$ y $20^{\circ} 57^{\prime \prime}$ de latitud norte y los meridianos $87^{\circ} 47^{\prime \prime}$ y $88^{\circ} 16^{\prime \prime}$ de longitud oeste (Figura 1). El área de estudio posee una extensión territorial de $1087.06 \mathrm{Km}^{2}$ y se encuentra integrado por 99 localidades, de las cuales Temozón (cabecera municipal), Nahbalam, Hunukú, Santa Rita y Yokdzonot Presentado son consideradas de mayor importancia (Gobierno del Estado de Yucatán, 2018).



Figura 1. Ubicación georreferenciada del Municipio de Temozón

Fuente: Google Maps 2020

El municipio de Temozón cuenta con 14,801 habitantes, distribuidos en 3,506 viviendas con un número promedio de 4.2 integrantes por vivienda (CONEVAL, 2010). Sus características sociodemográficas indican un alto grado de marginación, con más del $60 \%$ de la población mayor de 15 años analfabeta o con primaria trunca, viviendas de construcción endebles y en condiciones de hacinamiento (SEDESOL, 2016). 
La elección de esta población se basó en los siguientes criterios:

- $\quad$ Alto grado de marginación

- Existencia de Atlas de Peligros Naturales

- $\quad$ Alta incidencia de fenómenos naturales en la región (v.g. huracán Gilberto en 1988 con un alto impacto en la zona oriente de Yucatán).

- Interés de las autoridades municipales en el establecimiento de convenio para el desarrollo del proyecto.

Para la determinación de la muestra se utilizó la fórmula de estimación de tamaño de una muestra finita según Herrera (2011), cabe aclarar que la obtención de la muestra respectiva es para estimar el número de personas a encuestar en el municipio.

La fórmula utilizada para el cálculo de la muestra finita es:

\section{Ecuación 1.}

$$
n=\frac{N \sigma^{2} Z^{2}}{(N-1) \varepsilon^{2}+\sigma^{2} Z^{2}}
$$

Elementos de la fórmula:

$\mathrm{n}=$ tamaño de la muestra.

$\mathrm{N}=$ tamaño de la población o universo de trabajo.

$Z$ = constante asociada al nivel de confianza.

$\varepsilon=$ límite de aceptación del error muestral.

$\sigma=$ varianza de la población (varianza binomial de 0.25 ).

Aplicando la fórmula anterior y utilizando un $95 \%$ de confianza y $5 \%$ de error se obtuvo que el tamaño de la muestra es de 375 personas. Se realizó un muestreo estadístico aleatorio estratificado, segmentando a la población en subgrupos a los que se les denomina estratos. Para poder identificar la muestra dentro del estrato fue necesario realizar en cada localidad un muestreo aleatorio simple, es importante considerar que el número de elementos por estrato debe ser proporcional al tamaño de cada estrato (LCA, 2014).

En este estudio se eligió trabajar solo con los centros poblacionales que tengan más de 50 habitantes, con la finalidad de encontrar a las personas en sus hogares al momento de aplicar los cuestionarios (12 localidades en total; INEGI, 2010). Las comunidades se describen a continuación:

- Cabecera Municipal de Temozón, 6,553 hab.

- Hunukú. 2,971 hab.

- Nahbalam. 2,196 hab.

- Dzalbay. 552 hab.

- Yokdzonot Presentado. 490 hab.

- Santa Rita. 458 hab.

- Actuncoh. 420 hab.

- X-Uch. 303 hab.

- Ekbalam. 300 hab.

- X'Tut. 269 hab.

- San Basilio. 78 hab.

- X-Kanchechén. 50 hab.

Para determinar a las personas a las que se les aplicó el cuestionario se eligieron cuadras de manera aleatoria por cada localidad y se aplicó el instrumento a las viviendas al azar.

Se realizó una entrevista con preguntas predefinidas, al departamento de protección civil mediante una lista de verificación, y con una bitácora de observación se identificaron las condiciones físicas, ambientales, de salud, infraestructura y conectividad de las 12 comunidades estudiadas, lo que permitió obtener la información que se requiere para la variable de vulnerabilidad. 
La propuesta metodológica de este proyecto para el cálculo de las variables que determinan el riesgo (CENAPRED, 2014), y el análisis heurístico multicriterio fue elaborada considerando diversas metodologías en la materia, descritas en la Tabla 1.

\begin{tabular}{|c|c|c|c|}
\hline Método base & Dimensión & Instrumento & Variable \\
\hline $\begin{array}{l}\text { Marco de } \\
\text { Sendai }\end{array}$ & $\begin{array}{l}\text { Necesidad de conocer y comprender mejor el } \\
\text { riesgo en todas sus dimensiones (amenazas, } \\
\text { vulnerabilidad y exposición), fortalecer la } \\
\text { gobernanza en el tema, rendición de cuentas, } \\
\text { reconocimiento de los actores en el tema y } \\
\text { sus funciones, invertir en la prevención de } \\
\text { riesgos, trabajar en la resiliencia sanitaria, } \\
\text { patrimonio cultural, elaboración e implantación } \\
\text { de políticas para donantes sobre todo en } \\
\text { temas de apoyo financiero e impulsar las } \\
\text { plataformas regionales de reducción de } \\
\text { riesgos de desastres (UNISDR/GEI, 2015, } \\
\text { p.1). }\end{array}$ & $\begin{array}{l}\text { Cuestionario } \\
\text { Único Municipal. } \\
\text { Bitácora de } \\
\text { Observación. } \\
\text { Encuesta a la } \\
\text { Población. }\end{array}$ & $\begin{array}{l}\text { Exposición y } \\
\text { Vulnerabilidad }\end{array}$ \\
\hline $\begin{array}{l}\text { Modelo } \\
\text { Socorro } \\
\text { (2012), } \\
\text { basada } \\
\text { en ISO } \\
31000: 2009\end{array}$ & $\begin{array}{l}\text { La ISO } 31000 \text { se encuentra basada en buenas } \\
\text { prácticas internacionales para la gestión de } \\
\text { riesgos institucionales y gubernamentales, } \\
\text { particularizando en temas operativos y } \\
\text { dándole relevancia y compromiso a los } \\
\text { tomadores de decisiones (alta gerencia), } \\
\text { destaca en la metodología el uso del } \\
\text { ciclo del mejoramiento continuo "Deming" } \\
\text { (implementación, operación, mantenimiento y } \\
\text { mejora de un sistema de decisión de riesgos) } \\
\text { utilizados en las normas ISO, y centra su } \\
\text { planteamiento en revisión de información } \\
\text { documental (Norma ISO } 31000,2009 \text { ). }\end{array}$ & $\begin{array}{l}\text { Enfoque de } \\
\text { seguimiento y } \\
\text { propuestas de } \\
\text { mejora en el } \\
\text { manejo del Riesgo } \\
\text { Municipal. }\end{array}$ & Riesgo \\
\hline $\begin{array}{l}\text { CENAPRED } \\
(2014)\end{array}$ & $\begin{array}{l}\text { Fórmula de Riesgo = Amenaza (o peligro) x } \\
\text { Vulnerabilidad. } \\
\text { En el caso de los estudios de Peligros } \\
\text { y la Identificación de los Riesgos, para } \\
\text { la CENAPRED (2014) es importante } \\
\text { identificar y definir los posibles fenómenos } \\
\text { perturbadores en base a parámetros medibles } \\
\text { y cuantificables: } \\
\text { • Magnitud: "es una medida del tamaño del } \\
\text { fenómeno, de su potencial destructivo y de } \\
\text { la energía que libera"; } \\
\text { • Intensidad: "medida de la fuerza con que } \\
\text { se manifiesta el fenómeno en un sitio dado" } \\
\text { (p.8). }\end{array}$ & $\begin{array}{l}\text { Cálculo de las } \\
\text { matrices. } \\
\text { Todos los } \\
\text { instrumentos. }\end{array}$ & $\begin{array}{l}\text { Riesgo, Peligro, } \\
\text { Exposición y } \\
\text { Vulnerabilidad }\end{array}$ \\
\hline $\begin{array}{l}\text { Análisis } \\
\text { Heurístico } \\
\text { Multicriterio }\end{array}$ & $\begin{array}{l}\text { El enfoque, es identificar criterios básicos que } \\
\text { sirvan para hacer una selección posterior, y } \\
\text { con ellos estudiar cada opción para cada uno } \\
\text { de los criterios, usualmente los criterios no son } \\
\text { cuantificables (Green, 2003). } \\
\text { A los criterios se le otorgan ponderaciones } \\
\text { para que se refleje la importancia relativa de } \\
\text { su cumplimiento, las cuales se estandarizan } \\
\text { para obtener valores entre } 0 \text { al 1, por lo que } \\
\text { la matriz resultante de las puntuaciones } \\
\text { de elección de las opiniones y los criterios } \\
\text { ponderados son el punto de partida para } \\
\text { desarrollar un proceso de aprendizaje } \\
\text { reiterativo (MUFHRC, } 2014, \text { p.9). }\end{array}$ & $\begin{array}{l}\text { Diseño general } \\
\text { de todos los } \\
\text { instrumentos } \\
\text { y rúbrica de } \\
\text { evaluación. }\end{array}$ & $\begin{array}{l}\text { Peligro, Exposición } \\
\text { y Vulnerabilidad }\end{array}$ \\
\hline
\end{tabular}


Continuación

\begin{tabular}{llll} 
Método base & \multicolumn{1}{c}{ Dimensión } & Instrumento & Variable \\
\hline & $\begin{array}{l}\text { Para la evaluación de riesgos implica el } \\
\text { conocimiento de los peligros, de los elementos } \\
\text { expuestos y de sus vulnerabilidades, basado } \\
\text { en estudios técnicos anteriores (estudio de }\end{array}$ & Diseño general & \\
Informe semi- & suelos, estudio de los ecosistemas, etc.) & de todos los & Riesgo, \\
cuantitativo & que tienen relación directa o indirecta con & instrumentos & Peligro, Exposición \\
de evaluación & el fenómeno de origen natural y/o el área & y rúbrica de & y Vulnerabilidad \\
de riesgos & geográfica de estudio, así como su escala & evaluación. & \\
& $\begin{array}{l}\text { de trabajo (no detallada) que pueden ser } \\
\text { incorporados en el informe de evaluación de }\end{array}$ & & \\
& $\begin{array}{l}\text { riesgos por su utilidad (CENEPRED, 2014, } \\
\text { p. 19). }\end{array}$ & & \\
\hline
\end{tabular}

Tabla 1. Metodologías utilizadas en el diseño de los instrumentos de investigación Fuente: Autores, 2021.

Las etapas simplificadas de los procedimientos de este estudio fueron:

1. Vinculación: definición de necesidades con el mandante (autoridades municipales en coordinación con la población y las instituciones locales) y establecimiento del plan de trabajo.

2. Recopilación de información básica, general y de antecedentes por fenómenos naturales, revisión de fuentes documentales, bases de datos y digitales en el área de estudio.

3. Diseño se instrumentos y validación: Se diseñaron los instrumentos de investigación adaptados a las metodologías base (Tabla 1) e incorporando las necesidades de cumplimiento del Marco de Sendai y ODS.

4. Trabajo de campo: Aplicación de instrumentos de recolección de datos mediante la utilización de técnicas participativas con la población, como aplicación de cuestionarios y observación.

5. Estimación y Análisis de Riesgos por fenómenos naturales: mediante la base de datos atenida de los instrumentos de investigación y el análisis de matrices se realizó el cálculo de los 10 indicadores estudiados, las 3 variables y el riesgo por comunidad y municipio, en función del fenómeno natural más sobresaliente.

6. Socialización de resultados y propuesta de mejora: se realizó una reunión con el alcalde, director de UMPC y sociedad representativa para comunicar los resultados obtenidos, y realizar las recomendaciones pertinentes con relación a las necesidades de cumplimiento del Marco de Sendai y ODS.

Las variables a considerar en este estudio están en función al cálculo de indicadores que constituyen las variables peligro, exposición y vulnerabilidad, y siguiendo la metodología de análisis de riesgo de protección civil de México (CENAPRED, 2014) se calcula aplicando la siguiente ecuación:

\section{Ecuación 2.}

$$
R=P \times E \times V
$$

Donde;

$$
\begin{aligned}
& R=\text { Riesgo (probabilidad de ocurrencia). } \\
& P=\text { Peligro. } \\
& E=\text { Exposición. } \\
& V=\text { Vulnerabilidad. }
\end{aligned}
$$

Los tipos de peligros analizados fueron de origen natural, se seleccionaron los que se han tenido algún registro o percepción de ocurrencia en el estado de Yucatán: tormenta tropical, tormentas eléctricas, sequía, ciclones tropicales, sismos, hundimientos, deslizamiento de tierra (deslaves). A los peligros se les identificó su intensidad y período de ocurrencia. En la Tabla 2 se observa la definición y relación de variables e indicadores de estudio. 


\begin{tabular}{|c|c|c|c|c|}
\hline $\begin{array}{l}\text { Nombre de } \\
\text { la Variable }\end{array}$ & $\begin{array}{l}\text { Riesgo } \\
(\operatorname{Var} 0)\end{array}$ & $\begin{array}{l}\text { Peligro } \\
\text { (Var 1) }\end{array}$ & $\begin{array}{l}\text { Exposición } \\
\text { (Var 2) }\end{array}$ & $\begin{array}{c}\text { Vulnerabilidad } \\
\text { (Var 3) }\end{array}$ \\
\hline Definición & $\begin{array}{l}\text { Probabilidad de } \\
\text { ocurrencia de } \\
\text { daños o pérdidas } \\
\text { materiales o } \\
\text { humanas ante } \\
\text { los elementos } \\
\text { expuestos a un } \\
\text { peligro. }\end{array}$ & $\begin{array}{l}\text { Ocurrencia de } \\
\text { fenómenos } \\
\text { destructivos } \\
\text { medidos de manera } \\
\text { temporal, se } \\
\text { expresa en base } \\
\text { a la función de } \\
\text { probabilidad }\end{array}$ & $\begin{array}{l}\text { Cantidad de } \\
\text { elementos que } \\
\text { son susceptibles } \\
\text { a ser dañados o } \\
\text { presenten pérdidas } \\
\text { de tipo económico o } \\
\text { humano. }\end{array}$ & $\begin{array}{l}\text { Susceptibilidad o } \\
\text { propensión de los } \\
\text { bienes expuestos a } \\
\text { ser afectados. }\end{array}$ \\
\hline $\begin{array}{l}\text { Tipo de } \\
\text { Variable }\end{array}$ & Dependiente & Independiente & Dependiente & Dependiente \\
\hline Indicador & $\mathrm{n} / \mathrm{a}$ & $\begin{array}{l}\text { Intensidad } \\
\text { Frecuencia }\end{array}$ & Exposición & $\begin{array}{l}\text { Falta de prevención, } \\
\text { resiliencia, } \\
\text { conocimiento del } \\
\text { tema, carencia } \\
\text { socio-económica. } \\
\text { Falta de aplicación } \\
\text { de la gestión de } \\
\text { riesgo local y de los } \\
\text { ODS entre otros. }\end{array}$ \\
\hline
\end{tabular}

Tabla 2. Características de las variables de estudio

Fuente: Autores, 2021, con datos de CENAPRED, 2014

\section{Instrumentos de investigación}

Para poder obtener información para la recolecta de datos del proyecto se utilizaron tres tipos de instrumentos principales (Hernández-Sampieri \& Mendoza, 2018):

Investigación documental: estudios previos de análisis de riesgos, mapeo por medio de herramientas tecnológicas como los sistemas de información geográfica, y estrategias de gestión del riesgo previas en el municipio, a través de visitas presenciales a las dependencias y por medio de las páginas web (Secretaría de Desarrollo Urbano y Medio Ambiente del estado de Yucatán (SEDUMA) de la administración 2012-2018 y INEGI, 2010).

Cuestionarios aplicados a los habitantes de las zonas de estudio:

1. Formato de encuesta a la comunidad sobre la percepción del riesgo local relacionada a eventos naturales, probabilidad de ocurrencia, impactos y afectaciones sociales, ambientales y económicas, con el fin de estimar las variables de peligro, exposición y vulnerabilidad.

2. Lista de verificación basada en la metodología de auditorías ambientales para identificar el grado de cumplimiento del departamento de protección civil conforme a la legislación mexicana nacional y estatal.

3. Cuestionario único municipal, para determinar el grado de vulnerabilidad del municipio desde la perspectiva de los dirigentes de las alcaldías, basados en los indicadores de los Objetivos del Desarrollo Sostenible (ODS) y el Marco de Sendai.

Bitácora de observación, para la descripción de comportamientos o conductas manifiestas de las actividades antropogénicas, nivel económico, accesibilidad de las localidades más alejadas, señal de radio, señal de telefonía móvil, electricidad y servicio de agua, con el fin de conocer la vulnerabilidad física y de infraestructura real de las localidades estudiadas. Además, se consideraron aspectos relevantes relacionados con los objetivos del desarrollo sustentable: cobertura de servicios de salud, proporción de la población que vive a menos de $2 \mathrm{Km}$, medio de transporte, proporción de la población que vive en barrios marginales, asentamientos improvisados o viviendas inadecuadas, superficie forestal, proporción de tierras degradas, comunicación, organización social, representante de la comunidad, presencia de refugios temporales, calidad de la infraestructura.

Se utilizó el estadístico de Alfa de Cronbach para medir la confiabilidad de los cuestionarios utilizados (específicamente el Formato de Encuesta a la Población) obteniendo un puntaje de 0.9. 
La validez de los instrumentos (encuestas a la comunidad y cuestionario único al municipio) se realizó mediante la técnica de juicio de expertos, particularmente el método de agregados individuales que consiste en pedir a un grupo de expertos que dé una estimación directa de los ítems del instrumento de manera individual (Corral, 2009).

Los cuestionarios fueron aplicados por personal voluntario del Instituto Tecnológico Superior de Valladolid, Yucatán, pertenecientes a las Licenciaturas de Ingeniería Ambiental e Ingeniería Civil, a quienes se les dio una capacitación intensiva sobre el llenado de la encuesta y vaciado de la información. Cada voluntario recibió un número de cuestionarios correlativo en función de igualdades, con el fin de organizar de una manera conjunta el proceso de aplicación.

\section{Interpretación de resultados}

Se diseñaron rúbricas bajo la metodología de análisis heurístico multicriterio para la interpretación de los datos obtenidos por los instrumentos, para variable Peligro (Tabla 3), Exposición (Tabla 4) y Vulnerabilidad (Tabla 5). Las escalas cualitativas, numéricas (tipo Likert) y de probabilidad son usadas por CENAPRED (2014), para la identificación rápida de la respuesta y facilitar el vaciado de los datos obtenidos.

\begin{tabular}{|c|c|c|c|}
\hline Cualitativa & Numérica & Probabilidad & Consideraciones \\
\hline \multicolumn{4}{|l|}{ Frecuencia } \\
\hline Muy frecuente & 4 & $0.76-1.00$ & Ha ocurrido en el último año \\
\hline Frecuente & 3 & $0.51-0.75$ & Ha ocurrido 1 en 5 años \\
\hline Ocasional & 2 & $0.26-0.50$ & Ha ocurrido 1 en cada 50 años \\
\hline Poco frecuente & 1 & $0.00-0.25$ & Nunca ha ocurrido o 1 en 100 años \\
\hline \multicolumn{4}{|l|}{ Intensidad } \\
\hline Impacto Muy Alto & 4 & $0.76-1.00$ & $\begin{array}{l}\text { Ocasiona daños materiales recuperables a largo plazo } \\
\text { y pérdidas humanas }\end{array}$ \\
\hline Impacto Alto & 3 & $0.51-0.75$ & $\begin{array}{l}\text { Ocasiona daños materiales recuperables a mediano } \\
\text { plazo y pérdidas humanas }\end{array}$ \\
\hline Impacto Moderado & 2 & $0.26-0.50$ & $\begin{array}{l}\text { Ocasiona daños materiales recuperables a poco plazo } \\
\text { y no deja pérdidas humanas }\end{array}$ \\
\hline Impacto Bajo & 1 & $0.00-0.25$ & No ocasiona pérdidas materiales y humanas. \\
\hline
\end{tabular}

Tabla 3. Rúbrica para interpretar la matriz de riesgo Variable Peligro

Fuente: Autores, 2021, con datos de ODS (UN, 2015), Marco de Sendai (UNISDR/GEI, 2015) y CENAPRED (2014)

\begin{tabular}{|c|c|c|c|}
\hline Cualitativa & Numérica & Probabilidad & Consideraciones \\
\hline Muy Alto & 4 & $0.76-1.00$ & $\begin{array}{l}\text { Zonas con alto crecimiento poblacional. } \\
\text { Con el paso del fenómeno hay pérdidas humanas y } \\
\text { económicas. } \\
\text { La mayoría de las casas y edificios son destruidos o } \\
\text { seriamente dañadas. } \\
\text { Modificación total del paisaje dejándolo irreconocible. }\end{array}$ \\
\hline Alto & 3 & $0.51-0.75$ & $\begin{array}{l}\text { Pérdidas en vivienda como en los techos y paredes. } \\
\text { Al menos } 1 \text { fallecimiento cada } 5 \text { años, perdidas } \\
\text { económicos. } \\
\text { Se presenta pérdida de cobertura vegetal. }\end{array}$ \\
\hline Moderado & 2 & $0.26-0.50$ & $\begin{array}{l}\text { Ha ocurrido en zonas no urbanizadas, solo causando } \\
\text { modificación en el paisaje. } \\
\text { Daños considerables a árboles y arbustos ocasionales. } \\
\text { Caminos cerrados. }\end{array}$ \\
\hline Bajo & 1 & $0.00-0.25$ & No ha tenido afectaciones nunca. \\
\hline
\end{tabular}

Tabla 4. Rúbrica para interpretar la matriz de riesgo Variable Exposición

Fuente: Autores, 2021, con datos de ODS (UN, 2015), Marco de Sendai (UNISDR/GEI, 2015) y CENAPRED (2014) 


\begin{tabular}{|c|c|c|c|}
\hline Cualitativa & Numérica & Probabilidad & Consideraciones \\
\hline Totalmente & 4 & $0.76-1.00$ & $\begin{array}{l}\text { Desconocimiento total sobre las causas y consecuencias de } \\
\text { los desastres. No ha recibido información al respecto. } \\
\text { La población nunca ha sido capacitada. } \\
\text { No han recibido apoyo por parte de las autoridades para la } \\
\text { reconstrucción (nula resiliencia). } \\
\text { Muy bajo nivel socioeconómico. } \\
\text { Baja aplicación de los ODS. } \\
\text { Nula aplicación de la Gestión de Riesgos por el Municipio y } \\
\text { capacidad de Protección civil. }\end{array}$ \\
\hline Considerable & 3 & $0.51-0.75$ & $\begin{array}{l}\text { Escaso conocimiento sobre las causas y consecuencias de } \\
\text { los desastres. } \\
\text { Ha escuchado de la alerta temprana pero no tiene } \\
\text { información clara ni precisa sobre cómo actuar. } \\
\text { Ha recibido capacitación anual. } \\
\text { En alguna ocasión han recibido apoyo para la reconstrucción } \\
\text { por parte de las autoridades (poca resiliencia). } \\
\text { Nivel socioeconómico bajo. } \\
\text { Moderada aplicación de los ODS. } \\
\text { Escasa aplicación de la Gestión de Riesgos por el Municipio } \\
\text { y capacidad de Protección civil. }\end{array}$ \\
\hline Moderada & 2 & $0.26-0.50$ & $\begin{array}{l}\text { Es consciente sobre las causas y consecuencias de los } \\
\text { desastres. } \\
\text { Se encuentran informados sobre las alertas y comunicados } \\
\text { para esperar instrucciones. } \\
\text { Ha recibido capacitación semestral. } \\
\text { La mayoría de las veces han recibido apoyos por parte de } \\
\text { las autoridades para la reconstrucción (buena resiliencia). } \\
\text { Excelente aplicación de la Gestión de Riesgos por el } \\
\text { Municipio y capacidad de Protección civil. } \\
\text { Nivel socioeconómico medio. } \\
\text { Alta aplicación de los ODS. } \\
\text { Buena aplicación de la Gestión de Riesgos por el Municipio y } \\
\text { capacidad de Protección civil. }\end{array}$ \\
\hline $\begin{array}{l}\text { Nada } \\
\text { vulnerable }\end{array}$ & 1 & $0.00-0.25$ & $\begin{array}{l}\text { Conocimiento total de la población sobre las causas y } \\
\text { consecuencias de los desastres. } \\
\text { Se encuentra muy preparada ha recibido capacitación y } \\
\text { conoce los sitios a donde puede acudir en caso de requerirlo. } \\
\text { Ha recibido capacitación mensual, las autoridades } \\
\text { siempre están dispuestos a dar préstamos o apoyo para } \\
\text { la reconstrucción (excelente capacidad de recuperación o } \\
\text { resiliencia). } \\
\text { Nivel socioeconómico alto. } \\
\text { Muy alta aplicación de los ODS } \\
\text { Excelente aplicación de la Gestión de Riesgos por el } \\
\text { Municipio y capacidad de Protección civil. }\end{array}$ \\
\hline
\end{tabular}

Tabla 5. Rúbrica para interpretar la matriz de riesgo Variable Vulnerabilidad

Fuente: Autores, 2021, con datos de ODS (UN, 2015), Marco de Sendai (UNISDR/GEI, 2015) y CENAPRED (2014)

\section{Análisis de Datos}

En total se aplicaron 376 cuestionarios entre las 12 localidades estudiadas entre el 9 al 13 de julio de 2018. Para recopilar los datos obtenidos, se diseñó una plantilla en el programa MS Excel y el análisis estadístico de la información se realizó en el software IBM SPSS v.22. El análisis de las variables se realizó primero por comunidad (12 en total) y después por el total del municipio, cada una para el fenómeno natural con mayor percepción de afectación. Se emplearon variables de frecuencia para determinar variables dicotómicas, promedios para las variables con escala tipo Likert y moda para la pregunta tipo de fenómeno natural de la encuesta a la población. En general se analizaron los estadísticos descriptivos y se generaron los gráficos correspondientes. Los resultados de cada ítem se pasaron al programa de MS Excel, para la realización de la matriz de riesgo correspondiente al municipio de Temozón. 


\section{RESULTADOS}

\section{Encuesta}

En la Figura 2 se muestra la percepción de probabilidad $(\mathrm{P})$ de ocurrencia de los peligros naturales estudiados, siendo sequías $(P=0.525)$ el único fenómeno natural con una percepción frecuente o moderada, mientras que las tormentas tropicales $(P=0.475)$, eléctricas $(P=0.425)$ y huracanes $(P=0.4)$ son considerados de frecuencia media u ocasional (fenómenos naturales de tipo hidrometeorológicos). La percepción del peligro por fenómenos geológicos fueron ocasionales (hundimientos) a poco frecuentes (deslaves y sismos). Lo anterior puede explicarse por la naturaleza geológica del área de estudio, lejana de zonas sísmicas y sistemas montañosos de importancia , además por la presencia de un sistema de cuevas subterráneas (cenotes) cuyos techos son susceptibles a colapsar.

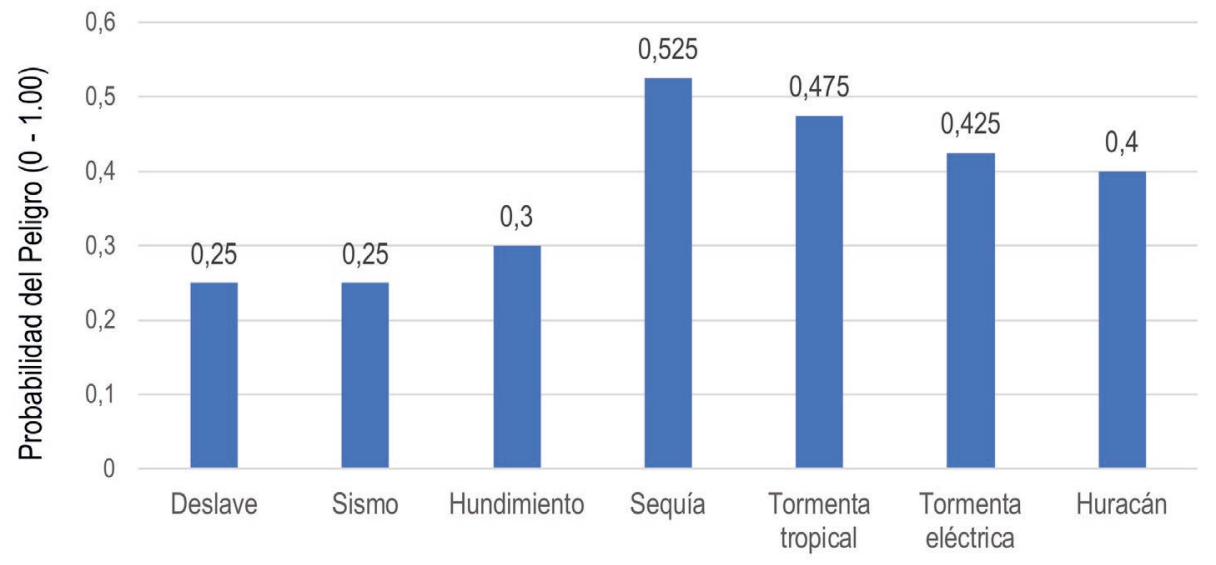

Figura 2. Percepción de la probabilidad de ocurrencia de Fenómenos Naturales en el municipio de Temozón Fuente: Autores, 2021

En el mismo sentido, la percepción del criterio Intensidad de los principales fenómenos que han afectado al municipio mostró en orden de importancia a los huracanes, tormentas tropicales, sequía y tormentas eléctricas (Figura 3).

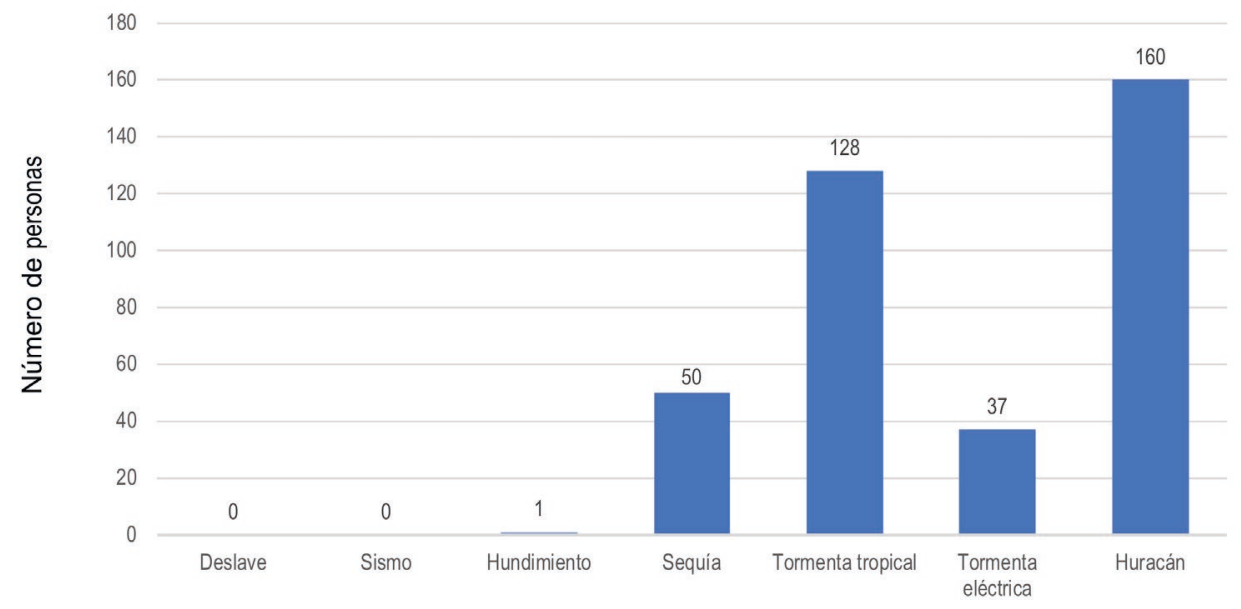

Figura 3. Percepción de la intensidad de los Fenómenos naturales en Temozón Fuente: Autores, 2021

Las principales afectaciones que ha dejado el paso de los huracanes como el principal fenómeno natural con mayor impacto en el municipio de Temozón se aprecian en la Figura 4. La afectación al suministro de agua es muy frecuente en el municipio después del paso de un huracán seguido de suspensión de actividades productivas y modificación del paisaje. Cabe aclarar que el suministro de agua está relacionado con la disponibilidad de la energía eléctrica para la operación de bombas de extracción y distribución de agua desde los pozos profundos hasta las poblaciones. 


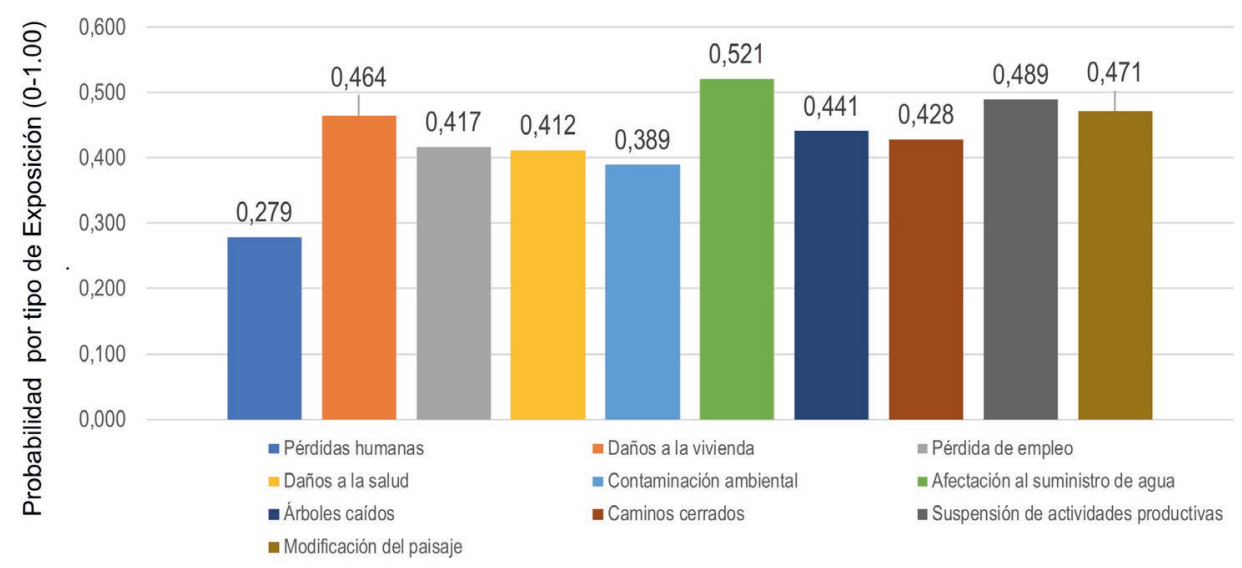

Figura 4. Tipo de afectación que ha tenido la población expuesta al paso de huracanes en el municipio de Temozón Fuente: Autores, 2021.

Los resultados obtenidos corroboran la información presentada en estudios previos, en cuanto a que la península de Yucatán ubicada en la región sureste de México es una de las principales zonas de embate de fenómenos naturales y se encuentra dentro de las 5 regiones con mayor exposición a fenómenos naturales de tipo hidrometeorológico del planeta (PNUD, 2009, p.17). Además presenta variación de la temperatura en diferentes temporadas estacionales lo que propicia periodos de incendios forestales y sequías. Durante el primero y segundo año después del paso de los huracanes más peligrosos de las ultimas 4 décadas como Gilberto en 1988, Opal-Roxane en 1994, Isidoro en 2002, Wilma-Stan en 2005, y Dean en 2007, se presentó gran incidencia de incendios forestales (lo que también causa modificación del paisaje y ecosistemas), consumiendo cerca de siete millones de hectáreas de selvas y pastizales entre 1992-2008. Así mismo el período de sequías se vio intensificado durante la periodicidad que comprende entre 1998-2009 causando daños graves a la población y economía de los estados de la región (Yucatán, Campeche y Quintana Roo). También disminuyó la producción granos y leguminosas (para autoconsumo), así como cultivos comerciales (café, cacao y miel) que son las principales fuentes de ingresos de las familias rurales en el sureste de México (PNUD, 2009).

\section{Matriz de ponderación de Riesgos}

En la Tabla 6 se presenta la matriz que se diseñó y utilizó para determinar las variables e indicadores de Riesgo Local para el municipio de Temozón y las 12 localidades estudiadas en relación al fenómeno natural de mayor impacto por cada centro poblacional.

Se determinó que los fenómenos naturales de mayor impacto son huracanes, tormentas tropicales, sequias y tormenta eléctrica. En caso de los fenómenos naturales más frecuentes son sequía, tormenta tropical y tormenta eléctrica. Además, según el análisis de riesgo se encontró que los huracanes son los fenómenos naturales de mayor impacto en la localidad.

El panorama general del municipio de Temozón en el manejo del riesgo local por fenómenos naturales es de consideración, ya que se observó un escenario promedio de riesgo alto (color naranja, probabilidad de 0.56). La percepción del peligro por parte de la población del municipio de Temozón es moderada (color amarillo, $\mathrm{P}=0.45$ ), dado que no se han presentado fenómenos naturales de importancia en más de 13 años (el último huracán de gran magnitud fue Wilma en 2005). La percepción de la población a estar expuesta a los peligros naturales es moderada ( $P=$ 0.44) principalmente por pérdidas de empleo, cosechas, falta de suministro de agua y cierre de carreteras, lo que afecta la comunicación y movilidad de los habitantes.

La variable vulnerabilidad para el municipio fue alta $(P=0.62)$, siendo de consideración la falta de prevención $(P=0.83$ ), poca capacidad de recuperación (resiliencia, $P=0.79$ ), falta de conocimiento en el tema de peligros naturales y gestión de riesgo local $(P=0.68)$ y las carencias socioeconómicas $(P=0.62)$. A excepción de las carencias socioeconómicas, los demás indicadores pueden mejorarse con la capacitación oportuna y constante en el manejo de la gestión de riesgo local, mediante el fortalecimiento, autonomía y empoderamiento de las comunidades para la toma de decisiones planeadas y coordinadas. Por otra parte, se observó una vulnerabilidad alta ( $P$ $=0.61$ ) con respecto al funcionamiento del departamento de protección civil, lo que indica que 
requiere fortalecer la capacitación y los canales de comunicación con las localidades. En relación a la infraestructura física de las localidades, la cabecera municipal obtuvo un puntaje de $\mathrm{P}=0.49$ (moderado), indicando una adecuada infraestructura, comunicación, suministro de servicios básicos y refugios temporales. Esto contrasta con lo observado en las localidades del interior del municipio en donde la mayoría son carentes en esos aspectos (se detallará más al hablar sobre la bitácora de observación). Con respecto a la gestión del presidente municipal en temas relacionados con fenómenos naturales, se obtuvo un puntaje de $\mathrm{P}=0.28$ (moderado), que indica que las acciones que conciernen al mandante municipal son cumplidas parcialmente (se detallará más en el apartado correspondiente).

\begin{tabular}{|c|c|c|c|c|c|c|c|c|c|c|c|c|c|c|c|c|c|c|c|}
\hline \multirow[b]{2}{*}{ 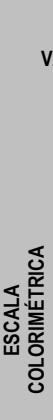 } & OR & ARAMÉTRIC & VP) $\downarrow$ & \multicolumn{3}{|c|}{ COMUNIDAD $\rightarrow$} & 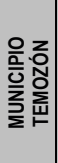 & 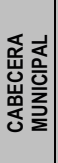 & $\begin{array}{l}\text { 록 } \\
\text { 主 } \\
\text { I }\end{array}$ & 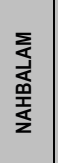 & 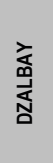 & 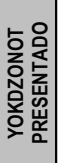 & 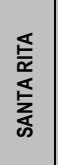 & 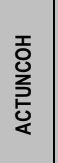 & 걿 &  & $\underset{x}{\stackrel{5}{\mathfrak{r}}}$ & 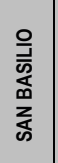 & 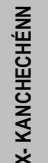 \\
\hline & 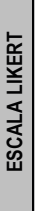 & 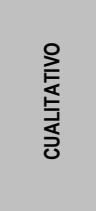 & 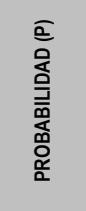 & \multicolumn{3}{|c|}{ PELIGRO IDENTIFICADO $\rightarrow$} & 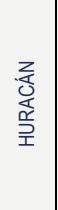 & 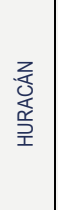 & 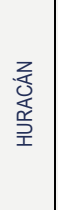 & 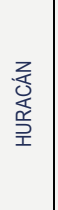 & 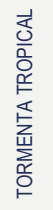 & 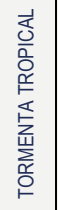 & 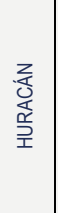 & 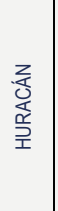 & 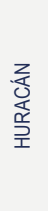 & 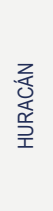 & 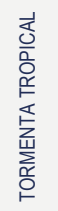 & $\begin{array}{l}\text { 通 } \\
\text { 岃 }\end{array}$ & $\begin{array}{l}\text { 莺 } \\
\text { 㟧 }\end{array}$ \\
\hline & & \multirow{4}{*}{ BAJO } & \multirow{3}{*}{$0-0.25$} & \multicolumn{3}{|c|}{ NIVEL DE RIESGO POR COMUNIDAD (P) $\rightarrow$} & \multirow{2}{*}{0.56} & \multirow{2}{*}{0.52} & \multirow{2}{*}{0.54} & \multirow{2}{*}{0.56} & \multirow{2}{*}{0.59} & \multirow{2}{*}{0.57} & \multirow{2}{*}{0.58} & \multirow{2}{*}{0.61} & \multirow{2}{*}{0.62} & \multirow{2}{*}{0.58} & \multirow{2}{*}{0.57} & \multirow{2}{*}{0.53} & \multirow{2}{*}{0.53} \\
\hline & 1 & & & VARIABLE $\downarrow$ & $\mathrm{P} \downarrow$ & INDICADORES $\downarrow$ & & & & & & & & & & & & & \\
\hline & & & & \multirow{2}{*}{ PELIGRO } & \multirow{2}{*}{0.45} & INTENSIDAD $\rightarrow$ & 0.48 & 0.51 & 0.40 & 0.31 & 0.75 & 0.67 & 0.64 & 0.63 & 0.65 & 0.50 & 0.50 & 0.50 & 0.51 \\
\hline & \multirow{3}{*}{2} & & \multirow{3}{*}{$0.26-0.50$} & & & FRECUENCIA $\rightarrow$ & 0.33 & 0.38 & 0.26 & 0.35 & 0.48 & 0.44 & 0.33 & 0.25 & 0.56 & 0.31 & 0.46 & 0.25 & 0.25 \\
\hline & & \multirow[t]{2}{*}{ MODERADO } & & EXPOSICIÓN & 0.44 & EXPOSICIÓN $\rightarrow$ & 0.46 & 0.49 & 0.4 & 0.44 & 0.40 & 0.38 & 0.48 & 0.48 & 0.40 & 0.44 & 0.45 & 0.47 & 0.47 \\
\hline & & & & \multirow{7}{*}{ VULNERABILIDAD } & \multirow{7}{*}{0.62} & PREVENCION $\rightarrow$ & 0.83 & 0.80 & 0.87 & 0.90 & 0.82 & 0.76 & 0.81 & 0.95 & 0.88 & 0.90 & 0.77 & 0.60 & 0.60 \\
\hline & & & & & & RESILIENCIA $\rightarrow$ & 0.79 & 0.70 & 0.91 & 0.90 & 0.70 & 0.69 & 0.78 & 0.96 & 0.91 & 0.90 & 0.77 & 0.50 & 0.50 \\
\hline & 3 & ALTO & $0.51-0.75$ & & & CONOCIMEINTO $\rightarrow$ & 0.68 & 0.65 & 0.71 & 0.72 & 0.72 & 0.62 & 0.70 & 0.76 & 0.71 & 0.75 & 0.70 & 0.70 & 0.70 \\
\hline & & & & & & SOCIOECONÓMICO $\rightarrow$ & 0.62 & 0.58 & 0.71 & 0.67 & 0.64 & 0.56 & 0.67 & 0.71 & 0.67 & 0.71 & 0.68 & 0.68 & 0.68 \\
\hline & \multirow{3}{*}{4} & \multirow{3}{*}{ MUY ALTO } & \multirow{3}{*}{$0.76-1$} & & & PROTECCION CIVIL $\rightarrow$ & 0.61 & 0.61 & 0.61 & 0.61 & 0.61 & 0.61 & 0.61 & 0.61 & 0.61 & 0.61 & 0.61 & 0.61 & 0.61 \\
\hline & & & & & & BITÁCORA (ODS) $\rightarrow$ & 0.49 & 0.24 & 0.27 & 0.40 & 0.50 & 0.70 & 0.50 & 0.47 & 0.54 & 0.37 & 0.51 & 0.74 & 0.70 \\
\hline & & & & & & PRESIDENTE $\rightarrow$ & 0.28 & 0.28 & 0.28 & 0.28 & 0.28 & 0.28 & 0.28 & 0.28 & 0.28 & 0.28 & 0.28 & 0.28 & 0.28 \\
\hline
\end{tabular}

Tabla 6. Matriz general de riesgos del municipio de Temozón Fuente: Autores, 2021.

\section{Lista de verificación}

La lista de verificación identificó que el departamento tiene conocimiento sobre eventos naturales, pero no tiene dominio de la legislación aplicable, como se observa en la Tabla 6 . El departamento de protección civil recae en una vulnerabilidad institucional alta, lo cual indica que hace falta capacitación en el manejo de las normas y legislación aplicable, así como en la falta de preparación antes, durante y después de un evento potencialmente dañino que derive de un fenómeno natural.

\section{Bitácora de observación}

La bitácora de observación se generó de la integración total de las 12 comunidades con respecto a las 10 consideraciones básicas de los objetivos del desarrollo sostenible. Se trata de una compilación con evidencia de las principales observaciones que se realizaron en la visita de campo que mide la vulnerabilidad física y de infraestructura de las localidades estudiadas.

Se puede destacar que las comunidades de Yokdzonot Presentado, X-Uch, X'Tut, San Basilio e X-Kanchechén se encuentran en un nivel de riesgo alto ante las inclemencias de un fenómeno natural de tipo hidrometeorológico (huracán, tormenta tropical y sequía), siendo Yokdzonot Presentado e X-Kanchechén a las que se considera que son más vulnerables a la ocurrencia de algún fenómeno natural, propiciada en su mayoría por la lejanía a la cabecera municipal, poca conexión en vías terrestres y de comunicación, así como la falta de servicios básicos e infraestructura para utilizar como refugios temporales.

Las localidades de Hunukú, Nahbalam, Dzalbay, Santa Rita, Actuncoh y Ekbalam presentan una vulnerabilidad moderada. 
Las comunidades de X-Uch y Actuncoh tienen mayor probabilidad de riesgo local $(P=0.62$ y 0.61 , respectivamente) para huracán. En el caso de las localidades de Dzalbay, X'Tut y Yokdzonot Presentado, se detectó que el fenómeno natural con más riesgo de ocurrencia fue tormenta tropical, y en las comunidades de San Basilio e X-Kanchechén la sequía, ambos fenómenos mencionados con probabilidad de ocurrencia alta, propiciados por la falta de conocimiento, resiliencia y prevención, indicadores pertenecientes a la variable vulnerabilidad.

Siete de las 12 localidades se encuentran en lugares remotos, poco conectadas vial y tecnológicamente, con poco contacto con la cabecera municipal para estar informados y preparados sobre los temas de riesgo local. Por lo que se considera que Temozón es un municipio vulnerable, con un nivel básico de educación, la mayoría de las personas trabajan en el sector primario, desconocen el nivel de riesgo a fenómenos hidrometeorológicos especialmente huracanes y tormentas tropicales al que están expuestos, a esto se suma la falta de medicamentos en los centros de salud, en las localidades más retiradas no cuentan con una clínica de salud, y falta del servicio de energía eléctrica a dos comunidades.

En caso de ser expuesto el municipio a un fenómeno natural como lo es un huracán o una tormenta tropical, la cabecera municipal es la que tiene mayor posibilidad de resistir este tipo de meteoro debido a que su infraestructura se encuentra en buen estado, los canales de comunicación son directos y es el punto de comando-control de la gestión de riesgo en el municipio.

\section{Cuestionario Único Municipal}

Este indicador se midió con la aplicación de un cuestionario al alcalde del municipio y se empleó con el fin de verificar el conocimiento que tienen los regidores y el presidente municipal como mandatario y responsable de toma de decisiones en el tema de gestión de riesgos y al mismo tiempo determinar el nivel de vulnerabilidad gubernamental en el que se encuentra el municipio ante eventos naturales. Los resultados mostrados en la Tabla 6 (apartado presidente), indican que las autoridades locales del municipio de Temozón tienen conocimiento moderado sobre riesgos naturales y realizan algunas acciones relacionadas con comunicar el peligro y preparación ante la emergencia, que impactan principalmente a la cabecera municipal. Entre las áreas de oportunidad que se detectaron está que la comitiva municipal (alcalde y regidores) no tienen total conocimiento sobre la aplicación de las legislación en materia de protección civil y emergencias ambientales, carecen de una estrategia municipal para prevenir los riesgos por fenómenos naturales, cuentan con el atlas de riesgos que data del 2013 pero no es utilizado, no tienen contratado seguros de daños por fenómenos climáticos, y la estrategia de recuperación (resiliencia) depende totalmente de las gestiones realizadas por el gobierno federal y estatal a través de las declaraciones de desastres y emergencias del FONDEN y del Fondo para la Prevención de Desastres Naturales (FOPRENDEN).

\section{DISCUSIÓN}

Se determinó que el nivel de riesgo para el municipio de Temozón enfocado a los huracanes está compuesto por las variables peligro, exposición y vulnerabilidad, con una ponderación de probabilidad de 0.56 , considerándose como de riesgo alto. Las personas entrevistadas son conscientes que los fenómenos de tipo hidrometeorológicos son catastróficos cuando ocurren, pero no necesariamente se siente en peligro inminente ya que no son frecuentes (Figura 2), lo que hace que los fenómenos naturales los tomen de sorpresa y este error humano hace que se concrete el desastre. Según Ramos, Olcian y Molina (2014) la experiencia con el riesgo hace que se incremente el nivel de percepción de riesgo, sugiriendo que una capacitación constante de la población al respecto sea necesaria para mantener vigente la memoria histórica de los desastres a nivel local.

De los peligros observados, los de tipo geológico (sismos, hundimientos y deslaves) son percibidos como poco frecuentes o nulos en la zona de estudio. No obstante, es de importancia incluirlos en el análisis dado que históricamente hay reportes de su ocurrencia (Pacheco et al., 2004), y a que los sismos ocurridos en septiembre de 2017 en el centro y sur de México y los de enero de 2018 y 2020 ocurridos en el Caribe, todos entre 7 a 8 grados de magnitud (Mw) fueron sentidos en varias ciudades de la península de Yucatán. Lo anterior puede derivar en derrumbes de cuevas, cavernas, bóvedas de cenotes y construcciones antiguas que abundan en el lugar de estudio, tal como se presentó en la iglesia de Nahbalam, Temozón construida en 1720, que colapso en octubre de 2018. Así mismo los peligros de tipo hidrometeorológico son los más frecuentes en la zona 
oriente del estado de Yucatán donde se encuentra el municipio de Temozón siendo las tormentas tropicales las más recurrentes y las que ocasionan más pérdidas económicas propiciadas por el deterioro del paisaje, afectaciones en la comunicación, obstrucción de vialidades e inundaciones, un claro ejemplo de esto es la pasada tormenta tropical Cristóbal que dejo lluvias torrenciales e inundaciones a su paso $(286.3 \mathrm{~mm}$ de lluvia acumulada solo en Valladolid, Yucatán, municipio aledaño a Temozón) y pérdidas de más de 5,422 millones de pesos en todo el estado (Diario de México, Universal \& Proceso, 2020). Sin embargo los huracanes son los fenómenos naturales más severos que pueden ocurrir en la zona de estudio, no son frecuentes (un huracán categoría 4 escala Saffir-Simpson ocurre en promedio cada 68.9 años para Valladolid), pero sus impactos son severos (APFNEY, 2012), según un estudio realizado por Appendini et al. (2019) demuestra que la península de Yucatán es más perceptible a afrontar ciclones tropicales más intensos y frecuentes, de intensificación rápida principalmente propiciado por los efectos del cambio climático, por lo que se espera que, en un futuro no muy lejano, se tengan eventos extremos en la zona de estudio, lo que no daría tiempo a una preparación ante la emergencia a corto plazo.

La variable exposición (de $\mathrm{P}=0.46$ a nivel municipal) que recae en moderado, es el resultado de la falta de conocimiento en el tema sobre los riesgos y peligros a los que se encuentra vulnerable la población, ante la falta de preparación a los posibles eventos naturales. Las principales condiciones que la población de Temozón se encuentra expuesta es la pérdida del suministro de agua, suspensión de actividades productivas, modificación del paisaje y daños a la vivienda, lo que pueden ocasionar otros problemas como incendios por corto circuito o forestales, problemas de salud pública por falta de agua potable y acumulación de agua de lluvia que derive en la proliferación de enfermedades gastrointestinales y dengue, la pérdida de empleo y viviendas, ocasiona más pobreza y hacinamiento en la población (APFNEY, 2012).

La variable vulnerabilidad es la más destacable en este estudio, obtuvo un puntaje de $P=$ 0.62 (considerado alto), los tipos de vulnerabilidades evaluados fueron la social o poblacional, institucional y físico o de infraestructura (incluye el aspecto ambiental, tecnológico, comunicación, edificaciones y vialidad). Sobre la vulnerabilidad social se sabe que la población del municipio de Temozón presentó bajo conocimiento sobre los temas relacionados al riesgo y los peligros por fenómenos naturales, han recibido poca o nula capacitación al respecto, y la relación con las instancias de protección civil o presidente municipal se encuentras distantes, lo que demuestra que en la administración municipal las decisiones en torno a la planificación y gestión de riesgos se encuentran centralizadas a la cabecera municipal, según Socorro (2012) las comunidades después de un desastres puede desarrollar los que se denomina "resiliencia comunitaria" es una forma de organización solidaria que presentan muchas comunidades latinoamericanas después de un evento catastrófico que ha ocasionado pérdidas humanas y económicas a movilizarse para reparar los daños y seguir adelante, por lo tanto, si esto ocurre naturalmente podría mejorar con el desarrollo de las competencias adecuadas a través de la capacitación e información constante en el tema, lo que sería una forma de prevenir el desastre.

La vulnerabilidad institucional medida por la evaluación realizada a la Unidad Municipal de Protección Civil (UMPC) y al gabinete municipal por medio del alcalde, muestra que se obtuvieron puntajes de vulnerabilidad alta y moderada respectivamente. En el caso de UMPC presenta capacitación en sus temas, pero la falta de experiencia del personal, nivel educativo y ocupando un cargo público con periodicidad de tres años hace que la persona en el puesto no sea competente y que el desarrollo de sus actividades se limite a atender de forma correctiva los posibles percances que se puedan reportar a la UMPC. Inclusive la confianza que deposita la población en el representante de la UMPC de desarrolla a través del constante trabajo recíproco entre el encargado de protección civil municipal y la comunidad, que se realiza a través del tiempo y las experiencias afrontadas, y no solo en un periodo de función pública de tres años, tal es el caso del estudio realizado por Soares, D., \& Murillo-Licea D. (2013) se evalúo el desempeño del responsable de la UMPC del municipio de San Felipe (Yucatán, México) que trabajaba en conjunto con representantes voluntarios del puerto para prevención de desastres, lo que la población calificaba bien y confiaban en su trabajo por la experiencia adquirida de más de 10 años en el cargo, en comparación del representante de UMPC de Ixil que solo se encontraba ocupando un cargo público por favoritismo político y no tenía el compromiso de servir a la población, este último fue calificado de manera reprobable.

La evaluación realizada al alcalde municipal y su gabinete refleja la falta de gestión municipal enfocado a la prevención del riesgo de desastres. El municipio que cuenta con su atlas de riesgo 
que no es utilizado y que no tienen a la mano, ya que existen malas prácticas entre los gobiernos locales de no dejar evidencias de las gestiones anteriores. Sin embargo, parte del estudio se encuentra disponible en internet y el CENAPRED, institución que en con junto con Secretaria de Desarrollo Agrario, Territorial y Urbano (SEDATU) financiaron los estudios en el sexenio anterior (2012-2018), quienes deben tener un respaldo. Así mismo las políticas nacionales tienen depositada poca responsabilidad en las municipalidades para el manejo de la gestión de riesgos, limitándolos a políticas orientadas a la reconstrucción después del desastre a través de los apoyos de FONDEN y FOPRENDEN. La inversión en la mejora de la infraestructura es una de las actividades que debe trabajar en las localidades del interior del municipio de Temozón. La mayoría tienen vías carreteras en mal estado e inseguras a su tránsito, los servicios de salud están centralizados, lo que significa que en caso de accidente o enfermedad los habitantes deben trasladarse a la cabecera municipal 0 al hospital general de Valladolid, además es necesario mejorar la tecnología para desarrollar una comunicación rápida y eficiente con las localidades más retiradas, permitiéndoles estar más preparados y capacitados ante algún fenómeno natural potencialmente catastrófico.

En el panorama internacional se tiene una nueva perspectiva del manejo de los riesgos de desastres a través de la aplicación del Marco de Sendai a los países miembros de la ONU desde 2015, por lo que México ya se encuentra trabajando en reestructurar su Sistema de Protección Civil y políticas públicas para atender la situación de desastres desde una manera integral y preventiva. En noviembre de 2019 se publicó la "Guía Municipal, Estrategia Municipal de Gestión de Riesgos de Desastres", en México, a manera de informar y aplicar gradualmente de forma voluntaria la estrategia de reducción de riesgos de desastres en los municipios desde una perspectiva local, especialmente aquellos que son menores 50,000 habitantes como es el caso de Temozón, por ser considerados los más vulnerables, lo que apoyará al empoderamiento y mejora continua de las políticas municipales a nivel local, para cumplir los objetivos del Marco de Sendai y de la Agenda 2030 para el Desarrollo Sostenible (ONU-Habitat \& Gobierno de México, 2019).

\section{CONCLUSIONES}

El trabajo presentado en este artículo señaló que el municipio de Temozón se encuentra en una ponderación de riesgo alta ante eventos naturales potencialmente severos (con una probabilidad de ocurrencia de riesgos por fenómenos naturales de entre 0.52 a 0.62 ) propiciada por la falta de prevención, resiliencia y conocimiento de la población (indicadores de la variable vulnerabilidad), lo que da cumplimiento a la hipótesis propuesta.

Para poder construir una gestión integral de riesgo de desastre a nivel local es importante reducir principalmente los factores de vulnerabilidad y exposición mediante la aplicación de políticas públicas sólidas que beneficien y trabajen en la preparación antes de la ocurrencia del desastre, el fortalecimiento de la UMPC, designación de un responsable con la experiencia y capacitación adecuada, y el empoderamiento de las comunidades para ser resilientes y autosuficientes en la preparación ante los riesgos de desastre. La mejora de la vulnerabilidad institucional es uno de los mayores retos que se destaca en los resultados obtenidos en esta metodología, por lo que es necesario realizar mayores gestiones para establecer mecanismos financieros, políticos y administrativos para implementar políticas de planeación territorial (Ordenamientos Ecológicos Territoriales OET, Planes de Desarrollo Urbano PDU y Atlas de Riesgos) que sean congruentes entre sí y que atiendan a las necesidades específicas de cada municipio, especialmente en aquellos más vulnerables.

Se recomienda aprovechar el interés existente de la población y la voluntad política para mejorar la gestión de riesgo local y reducir sustancialmente los riesgos de desastres, a través de capacitación y preparación ante emergencias tanto para fenómenos geológicos como hidrometerológicos, especialmente huracanes, tormentas tropicales, tormentas eléctricas y sequias. Adicionalmente, el municipio requiere de manera urgente un plan de gestión de riesgo local que pueda aplicar a sus comisarias con la finalidad de que estas se encuentren informadas y preparadas para la inminente ocurrencia de algún riesgo natural.

Sobre el desarrollo de la metodología, se sugiere que al replicar el estudio se realice a nivel población o comisaria para poder abarcar el 100\% de la población (a manera de censo), y que la unidad de estudio sea la vivienda y no la cantidad de pobladores, ya que las medidas de preparación para los posibles riesgos y peligros se deben hacer por vivienda, y de esta misma forma se puede ubicar oportunamente las familias que requieren mayor capacitación al respecto. 
La metodología propuesta permitió realizar un diagnóstico situacional del municipio de Temozón sobre las condiciones en las que se encuentra la gestión de riesgo local y reducción de riesgo de desastres, utilizando dos referentes internacionales, esto es, el Marco de Sendai y los Objetivos de Desarrollo Sustentable (ODS). Así mismo, se incorporaron adaptaciones que permitieron implementarla en forma real y sencilla, y cuantificando los resultados obtenidos, representando una herramienta de fácil utilización para poder realizar diagnósticos municipales en el tema. Ejemplo de lo anterior es que esta metodología de valoración de riesgo local actualmente está siendo replicada en otros municipios del oriente de Yucatán (México) como es el caso de Chichimilá y Valladolid, por las tendencias e interés municipal a dar cumplimiento a la agenda internacional desde la perspectiva local.

\section{AGRADECIMIENTOS}

Agradecimientos a las autoridades municipales, especialmente al presidente municipal del Honorable Ayuntamiento de Temozón, al Departamento de Protección Civil por creer y apoyar al proyecto tanto económica como administrativamente. Al Instituto Tecnológico Superior de Valladolid (ITSVA), representado por el Director General Lic. Mario Aralio Aguilar Díaz por impulsar los proyectos de investigación y especial mención a la Lic. Rubí Gutiérrez Terrones por el apoyo en la vinculación del proyecto con las áreas correspondientes. Especial reconocimiento al esfuerzo y apoyo que brindaron los estudiantes residentes de Ingeniería Ambiental: Roque Iraldo Rudo Balam y Manuel Jesús Chuc Chuc, así como a la alumna prestadora de servicio social Laura Isabel Moguel Cárdenas, también a los voluntarios que a continuación se mencionan: Edwin Eduardo Caamal Lázaro, Gerardo Daniel Pool Balam, Josué Javier Esquivel Manzanero, Juan Alejandro Infanson Torres, Samuel Jesús Chuc Pool, Yulitza Gizeli Hau Chimal, Nikte' Abigail Moo Kauil y María del Rosario Hau Cahum. A la Universidad Nacional Iberoamericana de México (UNINI MX) y la Fundación Universitaria Iberoamericana (FUNIBER), por la beca otorgada para la realización del doctorado vinculado a este trabajo.

\section{REFERENCIAS}

Appendini, C.M., Meza-Padilla, R., Abud-Russell, S., Proust, S. Barrios, R. \& Secaira, F. (2019). Efecto del cambio climático sobre los huracanes en la península de Yucatán. Climatic Change, 157, 469-482. https://doi.org/10.1007/s10584-019-02569-5

Centro Nacional de Prevención de Desastres CENAPRED, México. (2014). Diagnóstico de Peligros e Identificación de Riesgos de Desastres en México. Atlas Nacional de Riesgos de la República Mexicana. CENAPRED.

Centro Nacional de Estimación, Prevención y Reducción del Riesgo de Desastres CENEPRED, Perú. (2014). Manual para la Elaboración de Riesgos Originados por Fenómenos Naturales (2da Ed.). CENEPRED, Dirección de Gestión de Procesos (DGP), \& Subdirección de Normas y Lineamientos (SNL).

CONEVAL. (2010). Información anual sobre pobreza y rezago social Temozón. Consejo Nacional de Evaluación de la Política de Desarrollo Social. Disponible en: http://www.sedesol.gob.mx/work/ models/SEDESOL/Informes pobreza/2014/Municipios/Yucatan/Yucatan 085.pdf

Corral, Y. (2009). Validez y Confiabilidad de los instrumentos de medición para la recolección de datos. Revista de ciencias de la Educación, 19(33), 228-247. http://servicio.bc.uc.edu.ve/educacion/revista/ n33/art12.pdf

Cutter, S., \& Finch, C. (2008). Temporal and spatial changes in social vulnerability to natural hazards. Department of Geography, University of South Carolina.

Diario de México. (2020, 8 de junio). Tormenta tropical 'Cristóbal' dañó 95 mil hectáreas de cultivos en Yucatán. Diario de México. Disponible en: https://www.diariodemexico.com/ tormenta-tropical-cristobal-dano-95-mil-hectareas-de-cultivos-en-yucatan-gobernador

El Universal. (2020, 6 de junio). Tormenta tropical “Cristóbal” deja1o mil afectados en Yucatán ante contingencia por Covid-19. El Universal. Disponible en: https://www.eluniversal.com.mx/estados/ tormenta-tropical-cristobal-deja-10-mil-afectados-en-yucatan-ante-contingencia-por-covid-19

Federación Internacional de Sociedades de la Cruz Roja y de la Media Luna Roja IFRC. (2018). Informe Mundial de Desastres: Sin que nadie quede atrás. IFRC. Disponible en https://media.ifrc.org/ifrc/wpcontent/uploads/sites/5/2018/10/B-WDR-SP\%2oweb.pdf

IFRC. (2005). Base de datos relativa a los desastres. IFRC. Disponible en: https://www.ifrc.org/es/ publicaciones/disaster-law-database/ 
García Acosta, V. (2005). El riesgo como construcción social y la construcción social de riesgos. Desacatos, 19(3), 11-24.

Gobierno de la República de México. (2017). Avances y Resultados 2017 del Programa Nacional de Protección Civil 2014-2018. Plan Nacional de Desarrollo 2013-2018. Gobierno de la República de México. Disponible en: https://www.gob.mx/cms/uploads/attachment/file/309195/o4pe protecci n civilAyR2017.pdf

Gobierno del Estado de Yucatán. (2017, 20 de octubre). Ley de protección civil del estado de Yucatán. Decreto no.525/2017. Diario Oficial de la Federación. Disponible en: https://www. poderjudicialyucatan.gob.mx/digestum/marcoLegal/02/2017/DIGESTUM02356.pdf

Gobierno del Estado de Yucatán. (2018). Municipios de Yucatán, Temozón. Gobierno del Estado de Yucatán. Disponible en: http://www.yucatan.gob.mx/estado/ver municipio.php?id=85

Gobierno del Estado de Yucatán. (2012). Atlas de Peligros por Fenómenos Naturales del Estado de Yucatán. Gobierno del Estado de Yucatán \& Servicio Geológico Mexicano. Disponible en: http:// www.proteccioncivil.gob.mx/work/models/proteccioncivil/swbcalendario elementoseccion/535/ ii informe ejecutivo atlas de peligros por fen menos naturales del estado de yucat n.pdf

Google Maps. (2020). Mapa del municipio de Temozón. Google Maps. Disponible en: https://goo.gl/ maps/Zww1NuFe2WC8PQ4E8

Green, C.H. (2003). Handbook of Water Economics. John Wiley

Guha-Sapir, D., Hargitt, D., \& Hoyois, G., (2004). Thirty years of natural Disasters 1974-2003: The Numbers. Centre for Research on the Epidemiology of Disasters, UCL. Disponible en: https://www. unisdr.org/files/1078 8761.pdf

Hernández-Sampieri. R. \& Mendoza, C. (2018). Metodología de la Investigación (zera Ed). McGraw Hill.

Herrera, M.C. (2011). Fórmula para cálculo de la muestra poblaciones finitas. Postgrado de Pediatría, Hospital Roosevelt. Disponible en: https://investigacionpediahr.files.wordpress.com/2011/o1/ formula-para-cczarlculo-de-la-muestra-poblaciones-finitas-var-categorica.pdf

Instituto Nacional de Estadística y Geografía de México INEGI. (2010). Instituto Nacional de Estadística y Geografía. INEGI. Disponible en: https://www.inegi.org.mx/default.html

INEGI. (2011). Censo Nacional de Gobiernos Municipales y Delegacionales 2011. INEGI. Disponible en: https://www.inegi.org.mx/programas/cngmd/2011/

LCA. (2014). Tema 2. Muestreo, Estadística 4. Licenciatura en Ciencias Ambientales, UNEX. Disponible en: http://matematicas.unex.es/ mota/ciencias ambientales/tema2.pdf

MUFHRC. (2014). Herramienta de apoyo No. 2, Directrices para el Análisis Multicriterio en la Gestión de Riesgos de Inundación. Marco común de características de análisis coste-beneficio de la Gestión del Riesgo de Inundación. Floot Hazard Research Centre, Middlesex University.

ONU-Habitat \& Gobierno de México (2019). Guía Metodológica Estrategia Municipal de Gestión Integral de Riesgos de Desastres. Un paso a paso desde la identificación de los riesgos hasta la reconstrucción. ONU-Habitat \& Gobierno de México.

Organización Internacional para la Estandarización ISO. (2009). Norma ISO 3100o: Gestión del Riesgo Principios y Directrices. ISO.

Pacheco, J.F., Casiano, J., Pérez, S.J., Estrada, A.J., Cárdenas, A., Li, Y.T., Gutiérrez M.A., Rubí, B. \& Santiago, J.A. (2004). Sismicidad del Centro y Sur de México. Geos, 24(3), 457-461.

Programa de las Naciones Unidas para el Desarrollo PNUD. (2012). Conceptos Generales sobre Gestión del Riesgo de Desastres y Contextos en el País. Experiencias y herramientas de Gestión a nivel Regional y Local. PNUD.

PNUD. (2011). Informe sobre Desarrollo Humano 2011. Sostenibilidad y Equidad: Un mejor Futuro para Todos. PNUD.

PNUD. (2009). Transformar la Gestión Local de Riesgo. Programa de Manejo de riesgos de desastres en el sureste de México. PNUD.

Proceso. (2020, 20 de junio). Emiten declaratoria de desastres por daños causados por "Cristóbal” en Yucatán. 20 de junio de 2020. Proceso. Disponible en: https://www.proceso.com.mx/635164/ emiten-declaratoria-de-desastre-por-danos-causados-por-cristobal-en-yucatan

Ramos, R., Olcina, J. \& Molina, S. (2014). Análisis de la Percepción de Riesgos Naturales en la Universidad de Alicante. Investigaciones Geográficas, 61, 147-157. http://dx.doi.org/10.14198/ INGEO2014.61.10 
SEDESOL. (2016). Informe anual sobre pobreza y rezago social 2016. Secretaria de Desarrollo Social del Estado de Yucatán. SEDESOL. Dispinible en: http://www.inderm.yucatan.gob.mx/files-content/ general/7e5aiffff $315826 \mathrm{~b} 55$ f5 $87 \mathrm{fe} 18478 \mathrm{e} 5 \mathrm{c}$.pdf

Soares, D., \& Murillo-Licea D. (2013). Gestión de riesgo de desastres, género y cambio climático. Percepciones sociales en Yucatán, México. Cuadernos de Desarrollo Rural, 1o(72), 181-199.

Socorro Gómez D.E. (2012). Metodología para la gestión de riesgos de desastres en las comunidades, basado en el marco de acción de Hyogo 2005-2015. Ingeniería Industrial. Actualidad y Nuevas Tendencias, 3(8), 61-72.

Naciones Unidas UN. (2015). Objetivos del Desarrollo Sostenible (ODS). UN. Disponible en: https:// www.un.org/sustainabledevelopment/es/objetivos-de-desarrollo-sostenible/

Oficina de las Naciones Unidas para Reducción de Riesgos de Desastres UNISDR/GEI (2015). Marco de Sendai para la Reducción de Riesgos de Desastres 2015-203o. UNISDR. Disponible en: https://www. eird.org/americas/docs/43291_spanishsendaiframeworkfordisasterri.pdf 